\title{
A case study in sports law analytics: The debate on widespread point shaving
}

\author{
Richard Borghesi* \\ University of South Florida - Sarasota Manatee, Sarasota, FL, USA
}

\begin{abstract}
This study outlines the evolution of academic literature generated in response to Wolfers's (2006) widespreadpoint-shaving hypothesis, which put forward that roughly $1 \%$ of college basketball games involve gambling-related corruption. Researchers attempted to replicate Wolfers' findings in a variety of settings, examined the logistics involved in the act of point shaving, developed a theoretical model of team strategy, and used a variety of other novel approaches to better understand the root cause of the suspicious statistical anomalies identified. It offers evidence that sports analytics research is highly robust in academic settings because the methods employed and inferences drawn are subjected to the scrutiny of competing researchers having dissenting opinions and a strong incentive to publish.
\end{abstract}

Keywords: Basketball, gambling, replication, point shaving

Is it possible that point shaving is rampant in college basketball? In 2006 an unexpected 'yes' gave NCAA and law enforcement officials a scare and set off a flurry of activity among economists. For the next eight years academic researchers re-examined this issue from a variety of angles. Most of the resulting work found evidence refuting the surprising assertion. What is interesting to note is that there is a natural process in place in which sports analytics researchers scrutinize each other's work, in effect acting together as a group to ascertain the truth.

In this case that process led to a thought-provoking debate, set off by Justin Wolfers' (2006) forensic economics study in which he concluded that roughly 500 NCAA men's basketball games between 1989 and 2005 may have been fixed via point shaving. ${ }^{1}$ Point shaving is an athlete's act of intentionally underperforming in order to win a bet placed on the opposing

*Corresponding author: Richard Borghesi, University of South Florida - Sarasota Manatee, Sarasota, FL 34243, USA. Tel.: +1 941 359 4524; E-mail: borghesi@usf.edu.

${ }^{1}$ For a thorough review of forensic economic literature on a variety of topics see Zitzewitz (2012). team. Wolfers' work began with the premise that players are bribed to not cover the spread (a reduction of effort is the most effective way to influence game outcome), and that favorites are more likely to shave points than are underdogs (a player on a favored team can both win the game and collect a bribe by not covering the spread). His analysis showed that strong favorites win games outright as frequently as expected but fail to cover the spread more frequently than expected. Based on this peculiar distribution of game outcomes he concluded that point shaving may be far more widespread than previously believed. ${ }^{2}$

While the vast majority of economics research does not receive mainstream press coverage, media outlets such as The New York Times, Chicago Tribune, USA Today, and Sports Illustrated, among others, picked up this story. The implications were that 1) legitimate gamblers have been swindled out of hundreds of millions of dollars, 2) hundreds of college athletes have committed felonies, and 3) the outcomes of many sports contests are predetermined. The latter is of great

\footnotetext{
${ }^{2}$ For a review of documented college basketball point-shaving scandals see Chang and Sanders (2009).
} 
import because it erodes fan confidence that they are experiencing a legitimate competition and could potentially shrink the number of fans watching sports, thus reducing league advertising revenue and ticket sales. ${ }^{3}$ What followed in response was a flurry of research designed to determine whether Wolfers' assumptions and conclusions were accurate.

To begin, Borghesi (2008) determined that the suspicious patterns identified by Wolfers were also present in National Basketball Association (NBA) basketball and National Football League (NFL) football. ${ }^{4} \mathrm{He}$ argued that NBA and NFL athletes are already highly compensated and would have to risk their careers and prison time to shave points for a small amount of supplemental income (relative to their salaries and endorsement revenues). Therefore, while the patterns were pervasive, they were unlikely to be caused point shaving. However, Gibbs (2007) suggested that even highly-paid professional basketball players may shave points because 1) there exist marginal players who have no guarantees of future NBA salaries and 2) players become less likely to survive in the NBA as they age because their physical talents decline. He proposed that these factors would reduce the impact of potentially foregone earnings if one were caught cheating. However, it seems that the more marginal and older players become the less power they have to influence game outcomes.

Johnson (2009) took a different route, challenging that Wolfers' study was tainted by faulty statistics. First, focusing on heavy favorites introduced a regression effect which biased results. In defining 'strong favorites' Wolfers utilized the point spread, which represents the market's perception of team strength. However, bettors may overestimate the strength of dominant teams thereby resulting in more frequent failures to cover than otherwise. Second, because basketball games cannot end in ties the distribution of game outcomes relative to the spread is shifted, potentially leading Wolfers to erroneously reject the null hypothesis of no point shaving. Relatedly, Borghesi,

\footnotetext{
${ }^{3}$ Chang and Sanders (2009) presented a theoretical model in which point shaving corruption causes a net social loss. The authors also proposed a model that identifies corruptible NCAA basketball types (players who do not expect to enter the NBA but who play regularly on nationally-strong teams).

${ }^{4}$ Schmidt and Stuck (2009) showed that these patterns were absent in NCAA football and proposed that because a single basketball player has a greater impact on game outcome than does a single football player, point shaving is less likely to occur in football.
}

Paul, and Weinbach (2010) cast doubt on the soundness of Wolfers' critical assumption that, in the absence of point shaving, game outcomes would be symmetrically distributed about the spread. Examining data from six different sports leagues, the authors determined that the outcomes of totals bets are asymmetrical and suggest that a combination of the behavioral biases among bettors and the profit motive of bookmakers together cause bet outcome distributions to be asymmetrical around closing lines. 5

To further the debate, Borghesi and Dare (2009) showed that strong favorites allow underdogs to score fewer points than expected. This is exactly the opposite of what would be expected if point shaving were widespread. College basketball player Stevin Smith, who was at the center of the 1994 Arizona State point shaving scandal, told investigators that his primary means of manipulating game outcomes was to slack on defense, fearing that poor offensive production would be a stronger signal of point shaving. Borghesi and Dare suggested that optimizing strategies by coaches and players late in blowout games caused the unexpectedly large proportion of win-but-fail-to-cover outcomes. The leading team pursues a low-variance strategy (manages the clock by holding the ball longer and preventing the other team from gaining possession) while the trailing team purses a high-variance strategy (fouls repeatedly, shoots quickly, presses to force turnovers, and increases the frequency of threepoint attempts). Taking a novel approach, Bernhardt and Heston (2010) imputed point spreads for games which have no Las Vegas line by utilizing Sagarin Ratings. In such contests there is little incentive to shave points since the market for bets is either absent or thin (via a local bookmaker). However, they found very similar outcome distributions between games with lines and those without. They again conclude that the suspicious patterns described by Wolfers are caused by maximizing behavior late in games. Such behavior was later further supported via a theoretical model developed by Gregory (2011).

In 2011, Paul and Weinbach introduced an innovative data set to further explore the widespread-pointshaving hypothesis. If point shaving were pervasive, they proposed, one would expect to see that more bets are placed against large favorites (those in-theknow would place more bets on the underdog). Their

\footnotetext{
${ }^{5}$ Also called an over/under bet, the outcome of a totals wager depends on the combined scores of both teams in a contest.
} 
examination found no evidence of unusual betting frequencies involving large favorites. However, as noted by Diemer (2012), Paul and Weinbach's arguments would have been more compelling had they been able to examine the dollar volume bet (as opposed to the number of bets placed) on each side of the line. If a game were to be effectively fixed few gamblers would be in-the-know, otherwise the line would shift by too much causing profits to decline and risk of discovery to increase. ${ }^{6}$ It would be more intuitive that betting activity would come in the form of a single or very few bettor(s) placing larger wagers on the side of the underdog.

Recently, Diemer and Leeds (2013) isolated NCAA tournament games and found that the suspicious patterns were absent. They concluded that during post season competition each player's incentive to win increases thus decreasing their willingness to shave points. Alternatively, cheating is less attractive during widely-viewed events because there is greater scrutiny therefore a higher probability of being discovered. They also found evidence consistent with point shaving in the regular season both by favorites, who win by too little, and by underdogs, who lose by too much. However, their results can be largely explained by teams following win-maximizing strategies that result in peculiar outcome distribution patterns.

While the door is left open for further examination, the majority of follow-up studies have refuted Wolfers' original claim. This stream of research demonstrates that within the field of sports analytics there exists a checks-and-balances mechanism whereby peers closely monitor and effectively challenge each other's' work.

\section{References}

Bernhardt, Dan, Steven Heston, 2010. Point Shaving in College Basketball: A Cautionary Tale for Forensic Economics, Economic Inquiry. 48, 14-25.
Borghesi, Richard, 2008. Widespread Corruption in Sports Gambling: Fact or Fiction? Southern Economic Journal. 74 1063-1069.

Borghesi, Richard, William Dare, 2009. A Test of the WidespreadPoint-Shaving Theory, Finance Research Letters. 6, 115-121.

Borghesi, Richard, Rodney Paul, Andrew Weinbach, 2010. Totals Markets as Evidence Against Widespread Point Shaving, The Journal of Prediction Markets. 4, 15-22.

Chang, Yang-Ming, Shane Sanders, 2009. Corruption on the Court: The Causes and Social Consequences of Point-Shaving in NCAA Basketball, Review of Law and Economics. 5, 269-291.

Diemer, George, 2012. Comment on "Investigating Allegations of Point-shaving in NCAA Using Actual Sportsbook Percentages, Journal of Sports Economics. 13, 207-210.

Diemer, George, Michael Leeds, 2013. Failing to Cover: Point Shaving or Statistical Abnormality? International Journal of Sport Finance. 8, 175-191.

Gibbs, Jonathan, 2007. "Point Shaving in the NBA: An Economic Analysis of the National Basketball Association's Point Spread Betting Market.” Unpublished master's thesis, Stanford University.

Gregory, Jesse, 2011. Do Basketball Scoring Patterns Reflect Wide Spread Illegal Point Shaving? Unpublished working paper, University of Wisconsin - Madison.

Humphreys, Brad, Rodney Paul, Andrew Weinbach, 2014. Understanding Price Movements in Point-Spread Betting Markets: Evidence from NCAA Basketball, Eastern Economic Journal, forthcoming.

Johnson, Neal, 2009. NCAA "Point Shaving" as an Artifact of the Regression Effect and Lack of Tie Games, Journal of Sports Economics. 10, 59-67.

Levitt, Steven, 2004. Why Are Gambling Markets Organized So Differently from Financial Markets? The Economic Journal. 114, 223-246.

Paul, Rodney, Andrew Weinbach, 2011. Investigating Allegations of Point-shaving in NCAA Using Actual Sportsbook Percentages, Journal of Sports Economics. 12, 432-447.

Schmidt, Martin, Lee Stuck, 2009. Point Shaving: Corruption in NCAA Football? Economics Letters. 105, 90-92.

Wolfers, Justin, 2006. Point Shaving: Corruption in NCAA Basketball, The American Economic Review. 96, 279-283.

Zitzewitz, Eric, 2012. Forensic Economics, Journal of Economic Literature. 50, 731-769.

\footnotetext{
${ }^{6}$ Under the balanced book model of sport book behavior, lines shift in response to imbalanced betting on side of the favorite or underdog. If the balanced book model does not hold (Levitt (2004), Humphreys, Paul, and Weinbach (2014)) then this may not be the case.
} 